Neuroepidemiology 2014;43:272-273

DOI: $10.1159 / 000368834$

\section{Validity of DSM-5 Dementia Criteria for Population Research in India}

Aashrai S.V. Gudlavalleti, A.T. Jotheeswaran

Indian Institute of Public Health, Hyderabad, India

Most population-based studies from India have reported a low prevalence of dementia compared to American or European studies [1]. A speculation on this discrepancy impugned the validity of dementia diagnostic criteria (DSM-III and IV) in the Indian population [2]. Subsequently, a study investigating the validity of dementia diagnosis in the south Indian urban population reported poor predictive validity for DSM-IV in the three years follow-up [3]. This is mainly because, in India, although cognitive impairment/decline is noted by family informants, it is largely attributed to 'normal aging'. In some cases, the informants may have been reluctant to disclose their observations not wanting to hurt the sentiments of the elderly. Therefore, the DSM-IV dementia diagnostic criterion was found to be less sensitive in identifying early dementia cases in the community [3]. The DSM-5 was released in 2013. It introduced the terms - 'Mild' and 'Major' Neurocognitive Disorder (NCD). Major and Mild NCD consumed the terms 'dementia' and 'cognitive disorder not otherwise specified' which were used in DSM-IV, respectively [4]. In DSM-5, the criteria for dementia diagnosis were relaxed. The revised criteria allowed us to include individuals with less severe cognitive deficits than that required for DSM-IV diagnosis $[4,5]$. The DSM-5 was field tested in the United States and Canada [6], but this was a first attempt in India. We revisited our survey data collected between 2004 and 2006 and tested the validity of DSM-5 mild and major dementia diagnosis criterion in the Indian urban (Chennai) population. The characteristics of the sample and methodology are published elsewhere [7].

Our database comprised 1,005 individuals above the age of 65 who were interviewed from a predefined catchment population in Chennai, India. This corresponded to a response rate of $72 \%$ [3]. The calculations for sample size [7], the detailed report of the survey, and the characteristics of the catchment population are described elsewhere [3]. Four cases were excluded from the analyses due to the lack of sufficient information to classify the participants according to DSM-5. The same variables that were used for developing the DSM-IV dementia algorithm, were also used to create the DSM- 5 criteria to detect mild and major NCD: a) criterion $\mathrm{A} 1$ and criterion $\mathrm{B}$ were defined as RELSCORE $\geq 0.5$; b) criterion A2 was defined as COGSCORE less than 1.5 standard deviations from the mean for major NCD, and less than 1.0 standard deviations from the mean for mild NCD (stratified by age and education), and c) criteria $\mathrm{C}$ and $\mathrm{D}$ were the same as those used in the DSM-IV dementia algorithm reported earlier [8]. The prevalence of DSM-5 NCD among older people aged over 65 was (4.2\%), six times greater than the DSM-IV dementia prevalence (0.8\%); however, it was considerably lower than the $10 / 66$ survey dementia diagnosis (9\%). The reliability between DSM-5 major NCD compared with 10/66 dementia diagnosis was moderate $(\mathrm{k}=0.52, \mathrm{p}<0.001)$ (table 1). Although, the specificity of DSM-5 major NCD was high $(98.9 \%)$, the sensitivity of the criteria was low $(42.7 \%)$.

When mild and major NCD were combined in a single matrix, there was an improvement in sensitivity of combined NCD $(61.3 \%)$. In conclusion, the validity of DSM-5 in Indian population is not robust, although detection of dementia cases is much better compared to DSM-IV. Future DSM revisions should consider modification of the criteria to one that is culturally sensitive and appropriate even to low- and middle-income countries, particularly functional decline owing to cognitive decline. Including both major and mild neurocognitive disorders in community screening might give a better yield than using only major NCD.

Table 1. Validity of DSM-5 dementia criterion compared to 10/66-dementia diagnosis

\begin{tabular}{llllll}
\hline DSM-5 criteria & $\begin{array}{l}\text { Cases not } \\
\text { diagnosed with } \\
\text { dementia/major } \\
\text { NCD (\%) }\end{array}$ & $\begin{array}{l}\text { Diagnosed with } \\
\text { dementia/major } \\
\text { CD }(\%)\end{array}$ & $\begin{array}{l}\text { Kappa agreement } \\
\text { between 10/66 } \\
\text { dementia diagnosis } \\
\text { and DSM-5 (\%) }\end{array}$ & $\begin{array}{l}\text { DSM-5 } \\
\text { sensitivity } \\
(95 \% \text { CI) }\end{array}$ & $\begin{array}{l}\text { DSM-5 } \\
\text { specificity } \\
(95 \% \text { CI) }\end{array}$ \\
\hline $\begin{array}{l}\text { Major NCD } \\
\text { Mild + major NCD }\end{array}$ & $\begin{array}{l}959(95.8) \\
929(92.8)\end{array}$ & $\begin{array}{l}42(4.2) \\
72(7.2)\end{array}$ & $\begin{array}{l}0.52 *(94.7) \\
0.60^{*}(94.5)\end{array}$ & $\begin{array}{l}42.7(31.3-54.6) \\
61.3(49.4-72.4)\end{array}$ & $\begin{array}{l}98.9(98-99.5) \\
97.2(95.9-98.2)\end{array}$ \\
\hline
\end{tabular}

* Statistically significant $(\mathrm{p}<0.05)$.

\section{KARGER}

E-Mail karger@karger.com www.karger.com/ned
(C) 2014 S. Karger AG, Basel

0251-5350/14/0434-0272\$39.50/0
A.T. Jotheeswaran

Indian Institute of Public Health

Hyderabad (India)

E-Mail jothees.at@iiphh.org 


\section{References}

$\checkmark 1$ Ferri CP, Prince M, Brayne C, et al: Global prevalence of dementia: a Delphi consensus study. Lancet 2005;366:2112-2117.

$\checkmark 2$ Prince M: Methodological issues for population-based research into dementia in developing countries. A position paper from the 10/66 Dementia Research Group. Int J Geriatr Psychiatry 2000;15:21-30.

- 3 Jotheeswaran AT, Williams JD, Prince MJ: The predictive validity of the 10/66 dementia diagnosis in Chennai, India: a 3-year follow-up study of cases identified at baseline. Alzheimer Dis Assoc Disord 2010;24:296-302.

4 American Psychiatric Association: Diagnostic and statistical manual of mental disorders, ed 5. Washington, DC, American Medical Association, 2013.

5 American Psychiatric Association: Diagnostic and statistical manual of mental disorders, ed 4. Washington, DC, American Medical Association, 1994.

-6 Regier DA, Narrow WE, Clarke DE, et al: DSM-5 field trials in the United States and Canada, Part II: test-retest reliability of selected categorical diagnoses. Am J Psychiatry 2013;170:59-70.
7 Llibre Rodriguez JJ, Ferri CP, Acosta D, Guerra M, Huang Y, Jacob KS, Krishnamoorthy ES, Salas A, Sosa AL, Acosta I, Dewey ME, Gaona C, Jotheeswaran AT, Li S, Rodriguez D, Rodriguez G, Kumar PS, Valhuerdi A, Prince M; 10/66 Dementia Research Group: Prevalence of dementia in Latin America, India, and China: a population-based cross-sectional survey. Lancet 2008;372:464-474.

8 Prince MJ, de Rodriguez JL, Noriega L, Lopez A, Acosta D, Albanese E, Arizaga R, Copeland JR, Dewey M, Ferri CP, Guerra M, Huang Y, Jacob KS, Krishnamoorthy ES, McKeigue P, Sousa R, Stewart RJ, Salas A, Sosa AL, Uwakwa R; 10/66 Dementia research group: The 10/66 Dementia Research Group's fully operationalised DSM-IV dementia computerized diagnostic algorithm, compared with the 10/66 dementia algorithm and a clinician diagnosis: a population validation study. BMC Public Health $2008 ; 8: 219$. 